\title{
A refresher in research publication ethics
}

Getting a research paper published in a peer-reviewed journal may seem like a daunting and never-ending task but, in the end, it is the peer-review process that ensures good research practice. Guidelines for good research practice are, as a rule, available at the national level, issued by the national Advisory Board/Committee on Research Ethics (for example, in Australia, these are available from the National Health and Medical Research Council $\left.{ }^{(1)}\right)$. Ethically acceptable, reliable and credible research must conform to guidelines on good research practice. Ethics in the process of getting the research published are also covered in the same guidelines and, from the publisher's point of view, are regularly discussed in the meetings held by the Committee on Publication Ethics (COPE), open to all members, editors and publishers.

COPE recently held its first Asia Pacific seminar in Melbourne (14 November 2011), highlighting several issues in relation to publication ethics that we should all keep in mind as editors, reviewers and authors. Here we provide a refresher for our readers and contributors. The COPE website (http://publicationethics.org/) has helpful flowcharts outlining the steps for editors to follow if they are concerned about various ethical issues in relation to publications. Another useful resource for issues on publication ethics is the International Committee of Medical Journal Editors (ICMJE) website (http:// www.icmje.org/).

The most frequent question about ethics in research publication relates to conflict of interest (COI). A COI may arise when an author, reviewer or editor has a financial or personal relationship that may inappropriately influence his/her actions. This may be an author writing about a product or service that he/she has a financial interest in, an editor accepting for publication a manuscript written by his/her spouse, or a reviewer rejecting a good paper by someone with whom he/she is competing for research funds and kudos. The latter is more difficult to detect but underlies the existence of 'reviewers to exclude' in some manuscript submission processes.

A COI is not an admission of wrongdoing: some conflicts are unavoidable. But not declaring a COI is a wrongdoing. Just as an author needs to declare a COI, so an editor or reviewer having a COI with regard to a manuscript should declare this, and generally not be involved in the decision making.

Overall, authors seem to have learned well that all financial support for themselves and for their work needs to be revealed; the editors and reviewers can then determine whether the COI is sufficiently large that the work cannot be published in their journal.

Authorship is another area where questions about publication ethics often arise. It is inappropriate to include authors who have not contributed sufficiently to a paper in the author list, but it is equally inappropriate to omit from authorship or acknowledgements people who have made an important contribution to the work to be published. The ICMJE gives clear guidelines regarding authorship $^{(2)}$ :

Authorship credit should be based on 1) substantial contributions to conception and design, acquisition of data, or analysis and interpretation of data; 2) drafting the article or revising it critically for important intellectual content; and 3) final approval of the version to be published. Authors should meet conditions 1,2 , and 3 .

People who make a significant contribution but do not meet the authorship criteria should (only) be acknowledged. While it is not possible for editors to make decisions regarding authorship, declarations of authorship are, as a rule, required, and the role of the editor is to remind authors of these expectations.

Originality $v$. duplication of published work poses yet another ethical dilemma. Authors are generally asked to confirm that submitted work has not been published before. Editors and reviewers familiar with the literature may at times identify overlap with other publications by the same author and this can be queried. Editors may, in fact, ask for related manuscripts to be provided so as to ensure that the latest submission is sufficiently different from the others to warrant publication. Editors may further request that companion papers submitted to the same journal be combined. If authors wish to publish translations of their own papers, the ICMJE guidelines consider this acceptable, provided that the translations reference the original paper ${ }^{(3)}$.

Plagiarism or copying the work of other authors, including one's own previously published work without declaring it, is a serious offence and violation of publication ethics, which today takes place too often. In order to eradicate this phenomenon, some journals are already checking for duplication using specially designed software. Without a doubt, there will be increasing use of software to detect duplication ${ }^{(4)}$. As a preventive measure, it is the journal's responsibility to provide, in its 'information to authors', clear guidelines to avoid duplication and 
plagiarism, and we hope that these will carefully studied by all authors.

Good research practice is crucial to achieving ethically sound research and publication. Clearly, ethics in publishing follows from ethical behaviour during the research being described, and while Public Health Nutrition has not previously specified this in the instructions to authors or as a criterion for reviewers, it is time we included this. Following the example of other journal review systems, we shall aim to include a check box for the reviewer to rate whether ethical issues have been adequately addressed in the manuscript. This should include mention of ethical review board approval of the work, information on the consent process used for human subjects and a statement that the work has conformed to appropriate guidelines such as the World Medical Association Declaration of Helsinki for clinical trials ${ }^{(5)}$.

Before we finish our refresher on research publication ethics, we'd like to ask for a more vigilant eye from all contributors for errors in publications, whether as a result of accident, incompetence or purposeful fraud. In 2004, a letter published in Nature ${ }^{(6)}$ pointed out that of the ten articles published in one edition which included figures with error bars, only three had figure legends that described what the error bars were. This lack of information made the figures uninterpretable, but had obviously not been noted by reviewers, editors or authors. Information for authors (http://assets.cambridge.org/PHN/PHN_ifc.pdf) submitting to Public Health Nutrition provides guidelines to ensure that figures and tables are understandable without referring to the text. It is always better to avoid errors, but even if already published, we encourage our readers to comment and ask for corrections.

Scientific papers are one of the primary means of advancing our collective understanding and, as such, everyone involved in the process of publication has a responsibility to behave in an ethical and thoughtful manner to avoid bias and minimise errors. There are guidelines from COPE, ICMJE and our own journal to help us meet our obligations, but in the long run it is up to the individual to behave with integrity ${ }^{(7)}$.

\author{
Allison Hodge \\ Irja Haapala \\ Deputy Editors
}

Agneta Yngve

Editor-in-Chief

Geraldine McNeill

Marilyn Tseng

Deputy Editors

\section{References}

1. National Health and Medical Research Council, Australian Research Council (2007) Australian Code for the Responsible Conduct of Research. Canberra: Australian Government; available at http://www.nhmrc.gov.au/_files_nhmrc/ publications/attachments/r39.pdf

2. International Committee of Medical Journal Editors (2009) Uniform Requirements for Manuscripts Submitted to Biomedical Journals: Ethical Considerations in the Conduct and Reporting of Research: Authorship and Contributorship. http://www.icmje.org/ethical_1author.html (accessed December 2011).

3. International Committee of Medical Journal Editors (2009) Uniform Requirements for Manuscripts Submitted to Biomedical Journals: Ethical Considerations in the Conduct and Reporting of Research: Overlapping Publications. http://www.icmje.org/ethical_1author.html (accessed December 2011).

4. Errami M, Sun Z, George AC et al. (2011) Identifying duplicate content using statistically improbable phrases. Bioinformatics 26, 1453-1457.

5. World Medical Association (2011) WMA Declaration of Helsinki - Ethical Principles for Medical Research Involving Human Subjects. http://www.wma.net/en/30publications/ 10policies/b3/ (accessed December 2011).

6. Vaux DL (2004) Error message. Nature 428, 799.

7. Graf C, Wager E, Bowman A et al. (2007) Best Practice Guidelines on Publication Ethics: a publisher's perspective. Int J Clin Pract Suppl issue 152, 1-26. 